\title{
Affordable Production of Antioxidant Aqueous Solutions by Hydrodynamic Cavitation Processing of Silver Fir (Abies alba Mill.) Needles
}

\author{
Lorenzo Albanese ${ }^{1}$, Alessandra Bonetti ${ }^{2}$, , Luigi Paolo D'Acqui ${ }^{2}$, Francesco Meneguzzo ${ }^{1, *(1)}$ \\ and Federica Zabini ${ }^{1}$ \\ 1 Institute of Biometeorology, National Research Council, 10 Via Madonna del Piano, \\ I-50019 Sesto Fiorentino (FI), Italy; l.albanese@ibimet.cnr.it (L.A.); f.zabini@ibimet.cnr.it (F.Z.) \\ 2 Institute for Research on Terrestrial Ecosystems, National Research Council, 10 Via Madonna del Piano, \\ I-50019 Sesto Fiorentino (FI), Italy; alessandra.bonetti@cnr.it (A.B.); luigipaolo.dacqui@cnr.it (L.P.D.) \\ * Correspondence: f.meneguzzo@ibimet.cnr.it; Tel.: +39-392-985-0002
}

Received: 8 January 2019; Accepted: 4 February 2019; Published: 12 February 2019

\begin{abstract}
Extracts from parts of coniferous trees have received increased interest due to their valuable bioactive compounds and properties, useful for plenty of experimental and consolidated applications, in fields comprising nutraceutics, cosmetics, pharmacology, food preservation, and stimulation of plant growth. However, the variability of the bioactive properties, the complexity of the extraction methods, and the use of potentially harmful synthetic chemicals, still represent an obstacle to the spreading of such valuable natural compounds. Hydrodynamic cavitation is emerging as a promising innovative technique for the extraction of precious food components and by-products from waste raw material of the agro-food production chain, which can improve processing efficiency, reduce resource consumption, and produce healthy, high-quality products. In this study, a process based on controlled hydrodynamic cavitation was applied for the first time to the production of aqueous solutions of silver fir (Abies alba Mill.) needles with enhanced antioxidant activity. The observed levels of the in vitro antioxidant activity, comparable or higher than those found for reference substances, pure extracts, and other water extracts and beverages, highlight the very good potential of the hydrodynamic cavitation (HC) process for the creation of solvent-free, aqueous solutions endowed with bioactive compounds extracted from silver fir needles.
\end{abstract}

Keywords: Abies alba Mill.; antioxidant activity; coniferous trees; essential oils; flavonoids; food preservation; green extraction; hydrodynamic cavitation; nutraceutics; polyphenols

\section{Introduction}

Fir needles from different plant varieties share a long history of beneficial use for human health and other applications, deriving from the anti-inflammatory and antiseptic properties, later attributed to the respective essential oils (EOs), polyphenols and flavonoids, and linked to their antioxidant activity. Reports exist, dating back to the 16th century, about the use of fir parts for prophylaxis and treatment of various diseases [1,2], as well as for recreational purposes, in particular in spruce beer [3,4]. Indeed, spruce beer turned out to be an effective preservative against, and remedy for, scurvy [5], as well as for rheumatic joints, colds and venereal disease [6], with its use reported in many areas of the world $[4,5,7-10]$.

Nowadays, the genus Abies of the Pinaceae family consists of approximately 50 species, which are largely distributed in temperate and boreal regions of North and Central America, Europe, Asia, and North Africa, eight of which are endemic to the Mediterranean region [11]. The silver fir (Abies alba Mill.) species, which is of special interest to this study, is widespread in central Europe, as well as in 
mountainous regions such as Pyrenees, Carpathians, Balkans, Alps, and Italian Apennines at relatively high altitudes [12].

As of the late 2000s, plenty of studies had been carried out on the chemical composition of firs (Abies genus), leading to the identification of several secondary metabolites such as terpenoids, flavonoids, phenols, lignans, steroids, totalling 277 compounds from 19 plants (out of about 50 known worldwide) of Abies species, among which Abies alba Mill. Further information about the chemical composition of silver firs, and the related variability, is available in Appendix A.

The study of chemical composition, biological and pharmacological activities of the extracts isolated from needles, bark, and wood from different coniferous tree species, experienced renewed interest in recent decades, aimed at applications in the fields of nutrition, health and medicine [13]. Extracts from most of the fir species exhibited a wide range of remarkable biological activities, such as antiproliferative, antibacterial, anti-inflammatory, cardiovascular, and central nervous system activities, at least some of them likely mediated by the respective antioxidant activity [14].

Most of the studies focused on essential oils extracted from parts of fir plants by means of different techniques, such as steam distillation (the dominant technique), maceration, solvent extraction, cold pressing, supercritical fluids, rectification, enfleurage (use of odourless animal or vegetable fats), solid phase extraction, etc. [15]. On the other hand, the extraction of phenolic compounds made use of solvents such as methanol, ethanol, acetone, diethyl ether and ethyl acetate, which are potentially hazardous for the human health, often mixed with different proportions of water [16]. Beyond the inherent complexity, and the use (and subsequent removal) of potentially harmful chemicals, such selective extraction techniques need high processing temperatures, and long process times. Few phytochemical and biological studies focused also on aqueous extracts, showing interesting findings, which are especially relevant to this study. Further information about recent studies is available in Appendix B.

In most of the studies shortly discussed in Appendix B, the aqueous solutions including fir parts were manufactured by means of relatively complex processes. They included pulverization of the raw material, extraction in water (also tap water) by means of different techniques, concentration by drying (e.g., vacuum drying), sometimes filtering and/or lyophilisation, and finally, dispersion of the resulting material in tap or distilled water.

In this study, for the first time, a solvent-free, fast, unselective, scalable extraction process was tested for its potential to produce aqueous solutions based on silver fir (Abies alba Mill.) needles and boost the respective in vitro antioxidant activity. This process was based on controlled hydrodynamic cavitation (HC), an emerging technique with a short but successful history in the extraction of valuable biocompounds [17-19]. Beyond the resulting biologically relevant properties, the manufacturing process of the aqueous solutions is very important, in particular the respective scalability and cost, conditioning the overall feasibility, as well as the affordability of the final product.

The HC equipment did not include any proprietary component, whole fir needles were processed in tap water at low to moderate temperatures, without previous grinding or pulverization, and centrifuge separation was applied to isolate the liquid phase from the residual insoluble solids. Beyond the scientific interest, the proposed method could lead to practical developments, related to products of interest to the nutraceutical and pharmaceutical industries, as well as to applications in the fields of food conservation, plant growth stimulation, and forestry.

\section{Materials and Methods}

\subsection{HC Device and Method}

Figure 1 shows the experimental device implementing the HC-based process, including a closed hydraulic loop (total volume capacity around $230 \mathrm{~L}$ ) and a centrifugal pump $(7.5 \mathrm{~kW}$ nominal mechanical power, rotation speed $2900 \mathrm{rpm}$ ). Such a device was used to produce beer wort in 
past studies, to which reference is made for any detail, including all components and measurement devices [19-22], as well as the geometry of the Venturi-shaped cavitation reactor [23].

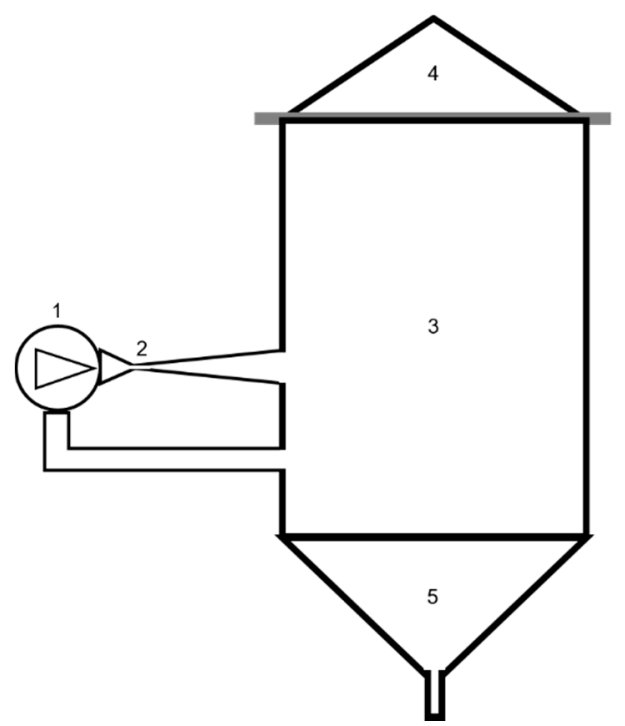

Figure 1. Experimental hydrodynamic cavitation (HC)-based installation. 1-centrifugal pump, 2-HC reactor, 3-main vessel, 4-cover, 5-discharge.

The cavitation process is associated with the heating of the liquid-solid mixture due to the thermal conversion of the pump's mechanical energy [19]. The tests were carried out under atmospheric pressure.

Theoretical background on the hydrodynamic cavitation processes was comprehensively exposed in many articles and reviews [18-20], with mechanical methods recognized as comparatively more efficient, robust and scalable [24]. As well, theoretical and experimental evidence has grown about the unique physical (mechanical and thermal) phenomena occurring at the scale of the collapsing cavitation bubbles $[25,26]$, and the chemical phenomena, such as water splitting and generation of powerful oxidants (e.g., $\mathrm{OH}$.hydroxyl radicals) $[25,27]$, the latter however quite limited in the absence of specific oxidizing additives $[28,29]$.

The main metric of HC processes, i.e., the cavitation number $(\sigma)$, was defined long ago [30]. It is a dimensionless parameter, derived from Bernoulli's equation, and representing the ratio between the pressure drop needed to achieve vaporization, and the specific kinetic energy at the cavitation inception section, as per Equation (1):

$$
\sigma=\left(\mathrm{P}_{0}-\mathrm{P}_{\mathrm{v}}\right) /\left(0.5 \cdot \rho \cdot \mathrm{u}^{2}\right)
$$

where $\mathrm{P}_{0}\left(\mathrm{Nm}^{-2}\right)$ is the average recovered pressure downstream of a cavitation reactor, such as a Venturi tube or an orifice plate, where cavitation bubbles collapse. Since the fluid was not pressurized, $\mathrm{P}_{0}$ was assumed equal to the atmospheric pressure. $\mathrm{P}_{\mathrm{v}}\left(\mathrm{Nm}^{-2}\right)$ is the liquid vapor pressure (a function of the average temperature for any given liquid). $\rho\left(\mathrm{kgm}^{-3}\right)$ is the liquid density, and $\mathrm{u}\left(\mathrm{ms}^{-1}\right)$ is the flow velocity through the nozzle of the cavitation reactor, the latter also depending on the pump's inlet pressure. In this study, the values of the cavitation number during the processes were computed according to the available data, such as temperature and pump discharge; the latter were retrieved based on the consumed power, as explained in a previous study [20].

The cavitation number has recently been placed under serious scrutiny over its representativeness and, in general, the reproducibility of HC processes [31]. However, under certain conditions, easily achievable with Venturi-shaped reactors, developed cavitation, with strong and frequent collapses of the cavitation bubbles, arises whenever the cavitation number falls within the range 0.1 to 1 , and even at greater values in the presence of solid particles or dissolved gases $[32,33]$. 


\subsection{Silver Fir Needles Samples and Tests}

Needles-carrying young twigs from lower branches of three adjacent silver firs, in practically identical amount from each tree $( \pm 5 \%$ in mass), were manually collected in mid-October 2018 . The silver fir trees belonged to a mixed beech tree-fir forest in northern Tuscany, Italy, near the village of Careggine $\left(44^{\circ} 06^{\prime} 15^{\prime \prime} \mathrm{N}, 10^{\circ} 20^{\prime} \mathrm{E}\right)$, at an altitude of about $1000 \mathrm{~m}$ a.s.l. on the north-eastern slopes of the Apuan Alps mountain range. The average annual climate was characterized by over $2000 \mathrm{~mm}$ rainfall [34], and temperature around $10^{\circ} \mathrm{C}$ [35]. Local fir species included silver fir and Douglas fir (Pseudotsuga menziesii), however only twigs from silver firs were harvested, and the respective needles used for the tests. Figure 2 shows a view of a portion of the fir forest (a), and a detailed view of silver fir twigs and needles (b).

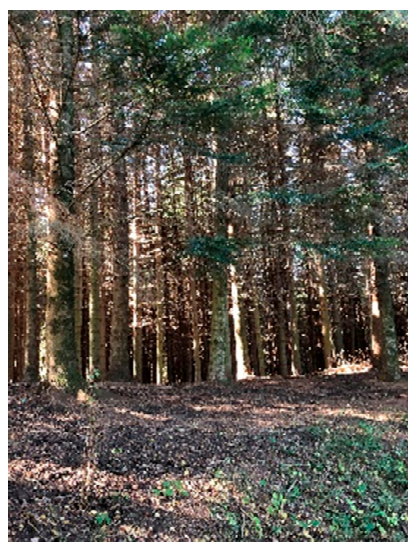

(a)

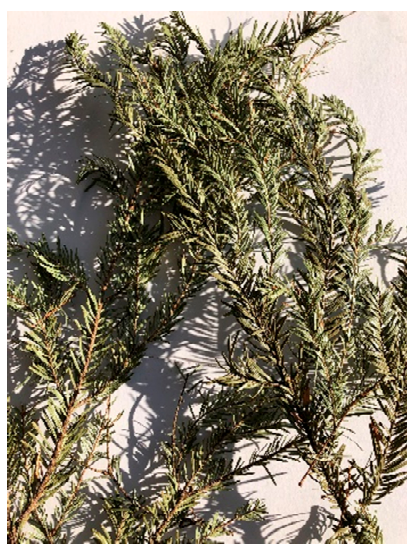

(b)

Figure 2. (a) View of a portion of the mixed firs forest; (b) silver fir twigs and needles.

Needles were manually removed from the twigs, until a batch of $5 \mathrm{~kg}$ was formed. Then, the same batch was gently mixed in a vessel by means of a magnetic stirrer at the minimum speed of $50 \mathrm{rpm}$, in order to preserve the needles integrity, while ensuring the batch homogeneity, and the representativeness of any extracted sample.

The first needles sample was extracted the day after the harvesting, with a water content of $30 \%$; since its mass was $0.756 \mathrm{~kg}$, the dry weight was $0.529 \mathrm{~kg}$. The second needles sample was extracted from the same homogenous batch, 40 days after the harvesting, during which the batch was kept at a constant temperature of $30 \pm 1{ }^{\circ} \mathrm{C}$, resulting in a water content of $2 \%$. The mass of the second needles sample was $0.540 \mathrm{~kg}$, resulting in the same dry weight as the first sample, i.e., $0.529 \mathrm{~kg}$.

Two tests were performed, hereinafter referred to as Silver Fir Needles-Test 1 (SFN_T1) and Silver Fir Needles-Test 2 (SFN_T2), both using 120 L of tap water as the only solvent, as well as carried out under atmospheric pressure. The test SFN_T1 used the first needles sample, while the test SFN_T2 used the second sample, therefore the silver fir needles were mixed with tap water in concentrations of $0.44 \%$ ( $w / w$ dry basis). Such relatively low concentration was dictated by the need to prevent clogging of the closed impeller pump; as explained in a previous study dealing with HC-based biochar modification [36], such concentration could easily be increased with the use of an open impeller pump.

The whole needles were mixed with water in the $\mathrm{HC}$ device from the beginning of each test, with SFN_T1 undergoing unconditioned heating from $27^{\circ} \mathrm{C}$ to $67.5^{\circ} \mathrm{C}$ during $90 \mathrm{~min}$, resulting from the balance between the mechanical energy supplied by the pump impeller and the heat loss through the uninsulated walls of the hydraulic circuit. In SFN_T2, the heating was unconditioned from $31.5^{\circ} \mathrm{C}$ up to the temperature of $43^{\circ} \mathrm{C}$, during $30 \mathrm{~min}$, then a further isothermal step was carried out at $43^{\circ} \mathrm{C}$ during $30 \mathrm{~min}$, with cooling water flowing in a jacket surrounding the $\mathrm{HC}$ device to remove the excess heat. 
Each sample, collected during the tests, was immediately centrifuged ( $3800 \mathrm{rpm}, 10 \mathrm{~min}$ ), and the supernatant was extracted for the measurements. The test samples were kept refrigerated in the dark at $4{ }^{\circ} \mathrm{C}$, and measured the day after each test, as well as later for stability assessment.

\subsection{Analytical Procedures}

\subsubsection{Total Phenolic Content}

The total phenolic content (TPC) was determined with the standard Folin-Ciocalteau assay [37]. A sample volume of $500 \mathrm{~mL}$ was added to $1 \mathrm{~mL}$ of distilled water in a $25 \mathrm{~mL}$ test tube. A volume of $2.5 \mathrm{~mL}$ of Folin-Ciocalteau reagent was added, and after $5 \mathrm{~min}$, a volume of $5 \mathrm{~mL}$ of $\mathrm{Na}_{2} \mathrm{CO}_{3}$ anhydrous solution was added, along with distilled water. Samples were read after $2 \mathrm{~h}$.

TPC was expressed as $\mathrm{mg}$ of Gallic acid equivalent per $\mathrm{mL}$ of aqueous solution $(\mathrm{mgGAE} / \mathrm{mL})$. A reference curve was prepared with Gallic acid concentration ranging from $0.1 \mathrm{mg} / \mathrm{mL}$ to $0.5 \mathrm{mg} / \mathrm{mL}$, and the solutions read at the wavelengths of 715,730 , and $760 \mathrm{~nm}$. Three curves were built, and the best fitting one, with $\mathrm{R}^{2}=0.9995$, was the one corresponding to $730 \mathrm{~nm}$, which was therefore assumed as the standard curve.

The absorbance of the colored reaction product was read at the $730 \mathrm{~nm}$ standard curve using a Varian UV-Visible spectrophotometer Cary 50 Scan. Each analysis was performed in triplicate.

\subsubsection{Total Flavonoid Content}

The total flavonoids content (TFC) was measured according to a standard procedure [38]. A quantity of $4 \mathrm{~mL}$ of distilled water, and $300 \mu \mathrm{L}$ of $\mathrm{NaNO}_{2}(5 \%)$, were added to $1 \mathrm{~mL}$ of water extracts of fir needles, and the samples were allowed to stand for $5 \mathrm{~min}$. Subsequently, $300 \mu \mathrm{L}$ of $\mathrm{AlCl}_{3}$ $(10 \%)$ were added, and samples were left to stand for $6 \mathrm{~min}$. Then, $2 \mathrm{~mL}$ of $\mathrm{NaOH} 1 \mathrm{M}$ were added to stop the reaction, and samples were brought to a final volume of $10 \mathrm{~mL}$ with distilled water. Samples were read after $15 \mathrm{~min}$.

TFC was expressed as $\mathrm{mg}$ of catechin equivalent (CE) per $\mathrm{mL}$ of aqueous solution $(\mathrm{mgCE} / \mathrm{mL})$, using an equation obtained by standard calibration graph with (+)-catechin. A reference curve was prepared with catechin concentration ranging from 0.02 to $0.1 \mathrm{mg} / \mathrm{mL}$, and solutions were read at the wavelengths of 500,510 , and $530 \mathrm{~nm}$. Three curves were built, and the best one with $R^{2}=0.9998$ was the one corresponding to $510 \mathrm{~nm}$, which was therefore assumed as the standard curve.

Samples were read at the $510 \mathrm{~nm}$ standard curve using a Varian UV-Visible spectrophotometer Cary 50 Scan. Each analysis was performed in triplicate.

\subsubsection{DPPH Radical Scavenging Assay}

The 2.20-diphenyl-1-picrylhydrazyl (DPPH) assay is commonly applied for the estimation of the antioxidant activity of plant extracts [39], and is related to the respective activity against lipid oxidation, which in turn affects food shelf life and human health [12,40]. The DPPH radical-scavenging activity was determined using a standard method [41].

A volume of $1 \mathrm{~mL}$ of DPPH solution was added to $1 \mathrm{~mL}$ of serially diluted samples. The obtained solution was read at a wavelength of $517 \mathrm{~nm}$, immediately after the addition of DPPH solution, and after keeping samples for $20 \mathrm{~min}$ in the dark, in order to measure the decreased absorbance of extract (AE).

The radical scavenging activity was calculated by the percentage of DPPH that was scavenged, using Equation (2):

$$
\% \text { Reduction }=[(\mathrm{AB}-\mathrm{AE}) / \mathrm{AB}] \cdot 100
$$

where $\mathrm{AB}$ is the absorbance of the blank sample, while $\mathrm{AE}$ is the absorbance of the water extracts. The Effective Concentration values (IC50), defined as the amount of antioxidant required to scavenge DPPH radicals by $50 \%$, were calculated from the results, and expressed as $\mu \mathrm{g}$ per $\mathrm{mL}$ of aqueous solution $(\mu \mathrm{g} / \mathrm{mL})$. Each analysis was performed in triplicate. 


\subsubsection{Oxygen Radical Absorbance Capacity (ORAC) Assay}

The oxygen radical absorbance capacity (ORAC) assay measures the scavenging of peroxyl as well as of hydroxyl radicals, and has been successfully applied to the assessment of antioxidant species in human plasma [42]. The ORAC measurement method was adapted from a previous work [43]. The instrument was a fluorescence spectrophotometer (Varian Cary Eclipse, Palo Alto, CA, USA). The sample $(150 \mu \mathrm{L})$ was added to a free-radical generator (AAPH, 2, 2'-azobis (2-aminopropane) dihydrochloride) $(75 \mu \mathrm{L})$, and the inhibition of the free radicals was measured. Fluorescein $(2.74 \mathrm{~mL})$ was used as a target for free-radical attack. The exciting wavelength was $490 \mathrm{~nm}$ and the emission wavelength was $512 \mathrm{~nm}$. Total antioxidant capacity, as measured by ORAC, was obtained using Equation (3):

$$
\text { ORAC }=20 \cdot \mathrm{k} \cdot\left(\mathrm{S}_{\mathrm{s}}-\mathrm{S}_{\mathrm{b}}\right) /\left(\mathrm{S}_{\text {Trolox }}-\mathrm{S}_{\mathrm{b}}\right)
$$

where $\mathrm{k}$ is the dilution factor, $\mathrm{S}_{\mathrm{s}}$ is the area under curve area of the sample, $\mathrm{S}_{\mathrm{b}}$ is the area of the blank under the curve, and $\mathrm{S}_{\text {Trolox }}$ is the area of the standard (Trolox, $1 \mu \mathrm{M}, 150 \mu \mathrm{L}$ ) under the curve. ORAC values were expressed as $\mu \mathrm{M}$ Trolox equivalents per Liter of aqueous solution ( $\mu \mathrm{MTE} / \mathrm{L})$, using the standard curve established previously. Each analysis was performed in triplicate.

\section{Results}

\subsection{Main Operational Parameters}

The cavitation number, computed according to Equation (1) and the method mentioned in Section 2.1, was in the range of 0.3 to 1.1 in both tests SFN_T1 and SFN_T2, thus falling in the range of developed cavitation, as defined in Section 2.1. Based on the estimated average flow $(330 \mathrm{~L} / \mathrm{min})$, and the water volume $(120 \mathrm{~L})$, the average frequency of passages through the cavitation reactor was about 2.75 per min.

The average power absorbed during SFN_T1 was around $5400 \mathrm{~W}$, with a total electricity consumption, during $90 \mathrm{~min}$ of process time, of $7.9 \mathrm{kWh}$. In test SFN_T2, the two quantities reduced to $4900 \mathrm{~W}$, and $4.56 \mathrm{kWh}$ (in $60 \mathrm{~min}$ of process time), respectively.

\subsection{Total Phenolic and Flavonoids Content}

Figure 3a shows the joint evolution of temperature and TPC, for tests SFN_T1 and SFN_T2. The same holds for Figure 3b, except that the evolution of TFC is represented.

In SFN_T2, the evolution of the total phenolic content exhibited a rapidly growing trend during the unconditioned heating step during the first $30 \mathrm{~min}$, doubling to $0.10 \mathrm{mgGAE} / \mathrm{mL}$ with temperature rising from $33{ }^{\circ} \mathrm{C}$ (after 5 min of process time) up to $43{ }^{\circ} \mathrm{C}$. In SFN_T2, the growth in TPC was insignificant up to the temperature of $40^{\circ} \mathrm{C}$. This result could be due to slightly higher working temperatures in SFN_T2.

Later on, in SFN_T1, with the further unconditioned heating to $47^{\circ} \mathrm{C}$ ( $45 \mathrm{~min}$ of process time), the respective TPC increased abruptly by nearly $100 \%$, up to $0.12 \mathrm{mgGAE} / \mathrm{mL}$, then oscillating between 0.10 and $0.14 \mathrm{mgGAE} / \mathrm{mL}$ up to the temperature of $67.5^{\circ} \mathrm{C}$, reached after $90 \mathrm{~min}$ of process time. In SFN_T2, during the $30 \mathrm{~min}$ of isothermal step at the temperature of $43^{\circ} \mathrm{C}$, TPC increased further, up to the level of $0.13 \mathrm{mgGAE} / \mathrm{mL}$, achieved after $60 \mathrm{~min}$ of total process time.

The preliminary conclusion can be drawn, that TPC increased with both temperature and cavitation time, but only up to temperature levels of, or below, $47^{\circ} \mathrm{C}$. No peak in TPC was detected for SFN_T1 in Figure 3a, suggesting that a longer cavitation time at the constant temperature of $43^{\circ} \mathrm{C}$ could lead to further increase in TPC. 


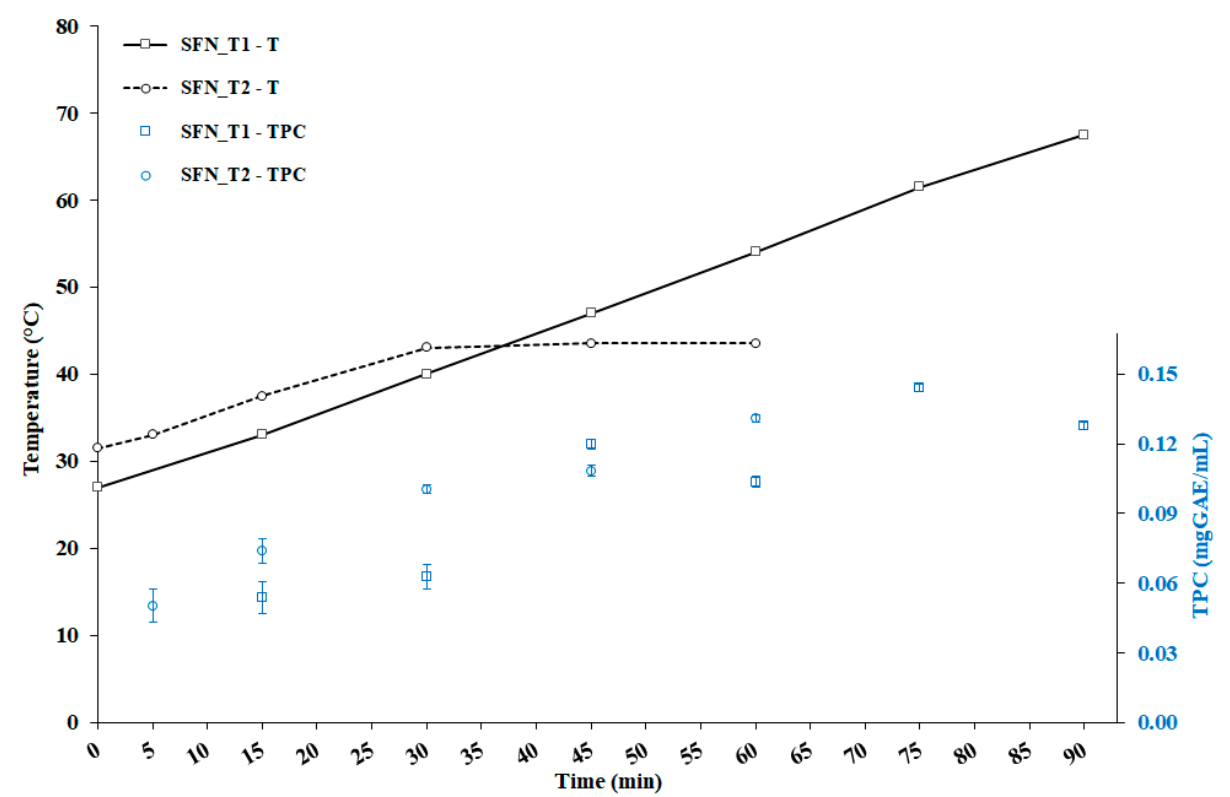

(a)

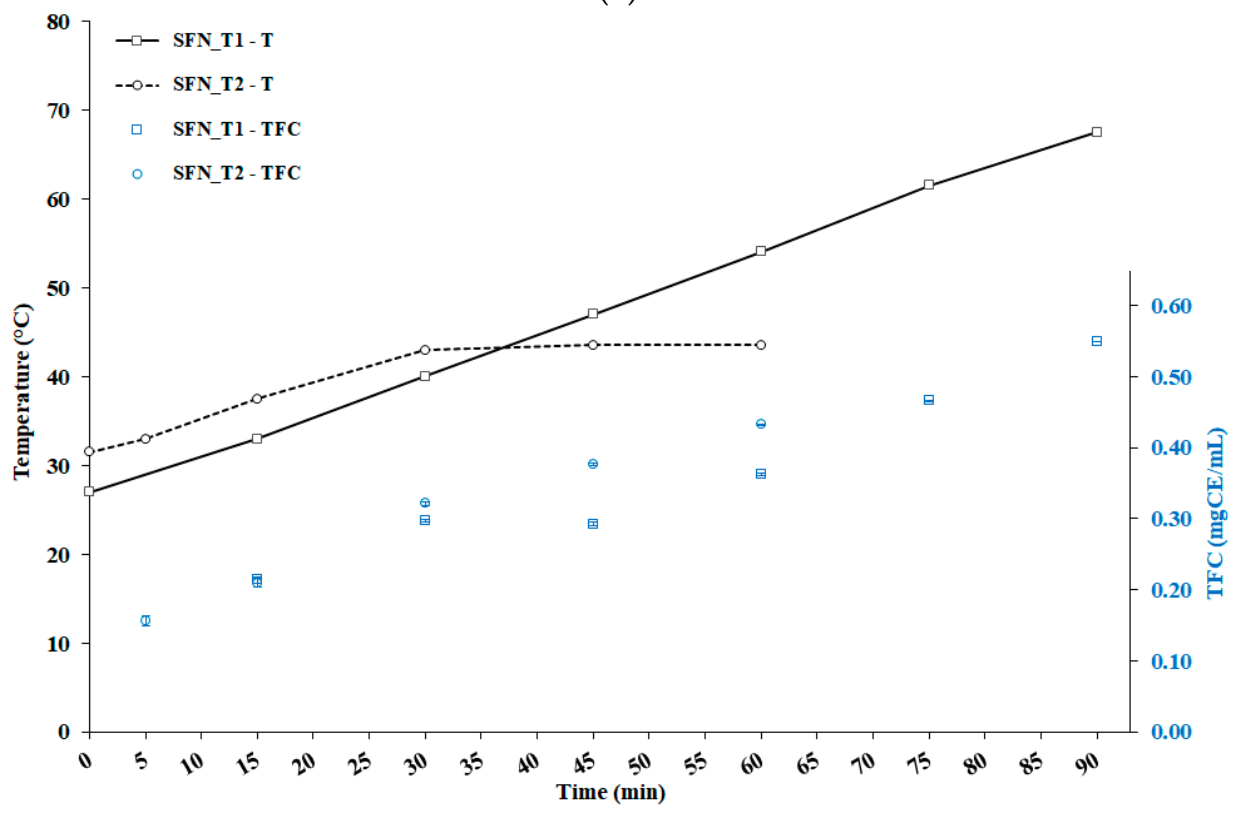

(b)

Figure 3. (a) Joint evolution of temperature (T) and total phenolic content (TPC) for tests SFN_T1 (Silver Fir Needles-Test 1) and SFN_T2 (Silver Fir Needles-Test 2); (b) Joint evolution of temperature (T) and total flavonoids content (TFC) for tests SFN_T1 and SFN_T2. Error bars represent the standard deviations.

The evolution of the total flavonoids content exhibits very similar, strong and significant growing trends during the unconditioned heating step in the first $30 \mathrm{~min}$, up to the temperature of $40{ }^{\circ} \mathrm{C}$ for SFN_T1 (with $0.30 \mathrm{mgCE} / \mathrm{mL}$ ), and $43^{\circ} \mathrm{C}$ for SFN_T2 (with $0.32 \mathrm{mgCE} / \mathrm{mL}$ ). Later on, in SFN_T2, during the $30 \mathrm{~min}$ of isothermal step at the temperature of $43^{\circ} \mathrm{C}$, TFC kept on growing almost linearly in time, up to $0.43 \mathrm{mgCE} / \mathrm{mL}$ (60 min of process time), and no evidence of peak arose. In SFN_T1, the TFC growth paused when temperature increased from $40^{\circ} \mathrm{C}$ to $47^{\circ} \mathrm{C}$, then grew again, almost linearly in time, up to the level of $0.55 \mathrm{mgCE} / \mathrm{mL}$, achieved at the temperature of $67.5^{\circ} \mathrm{C}(90 \mathrm{~min}$ of total process time), again without an apparent peak. 
The preliminary conclusion can be drawn, that TFC definitely increased with both temperature and cavitation time, but the isothermal step at $43^{\circ} \mathrm{C}$ seems more effective in the extraction of flavonoids.

\subsection{Antioxidant Activity}

Tables 1 and 2 shows the antioxidant activity, according to the DPPH and ORAC assays, observed for samples extracted during the tests SFN_T1 and SFN_T2, respectively. Measurements were performed the day after each test.

Table 1. 2.20-diphenyl-1-picrylhydrazyl (DPPH) and oxygen radical absorbance capacity (ORAC) antioxidant activities, with the respective standard deviations, for test SFN_T1 (Silver Fir Needles-Test 1). Superscripts indicate indistinguishable values $(p>0.05)$.

\begin{tabular}{cccc}
\hline Time (min) & T $\left({ }^{\circ} \mathbf{C}\right)$ & DPPH $(\mathbf{I C 5 0}, \mu \mathbf{g} / \mathbf{m L})$ & ORAC $(\mu \mathbf{M T E} / \mathrm{L})$ \\
\hline 0 & 27.0 & & \\
15 & 33.0 & $16.5 \pm 1.0^{\mathrm{a}}$ & $201.7 \pm 14.0^{\mathrm{b}}$ \\
30 & 40.0 & $14.4 \pm 0.7^{\mathrm{a}}$ & $163.0 \pm 11.4^{\mathrm{b}}$ \\
45 & 47.0 & $10.1 \pm 0.4$ & $184.6 \pm 12.9^{\mathrm{b}}$ \\
60 & 54.0 & $44.0 \pm 2.1$ & $457.9 \pm 24.1^{-1}$ \\
75 & 61.5 & $150.5 \pm 8.4$ & $585.9 \pm 27.1$ \\
90 & 67.5 & $350.8 \pm 23.7$ & $295.4 \pm 18.7$ \\
\hline \multicolumn{5}{c}{}
\end{tabular}

Table 2. DPPH and ORAC antioxidant activities, with the respective standard deviations, for test SFN_T2 (Silver Fir Needles-Test 2). Superscripts, in any column, indicate indistinguishable values $(p$ $>0.05)$.

\begin{tabular}{cccc}
\hline Time $(\mathbf{m i n})$ & T $\left({ }^{\circ} \mathbf{C}\right)$ & DPPH $(\mathbf{I C 5 0}, \mu \mathrm{g} / \mathbf{m L})$ & ORAC $(\mu \mathbf{M T E} / \mathbf{L})$ \\
\hline 0 & 31.5 & & \\
5 & 33.0 & $27.4 \pm 1.6^{\mathrm{a}}$ & $190.6 \pm 7.3^{\mathrm{c}}$ \\
15 & 37.5 & $19.5 \pm 0.9^{\mathrm{a}}$ & $186.6 \pm 18.1^{\mathrm{c}}$ \\
30 & 43.0 & $19.5 \pm 0.9^{\mathrm{a}}$ & $393.8 \pm 25.6$ \\
45 & 43.0 & $13.7 \pm 0.5^{\mathrm{b}}$ & $497.9 \pm 22.8$ \\
60 & 43.0 & $14.7 \pm 0.8^{\mathrm{b}}$ & $840.8 \pm 31.4$ \\
\hline
\end{tabular}

First, it is remarkable that after only 15 min of process time, both tests resulted in levels of the IC50 for the DPPH antioxidant activity below $20 \mu \mathrm{g} / \mathrm{mL}$. It is the same level attributed to ascorbic acid [44].

In SFN_T1 (Table 1), the DPPH assay showed a decrease of the respective IC50 level (increase of the antioxidant activity) from the temperature of $40{ }^{\circ} \mathrm{C}$ to $47^{\circ} \mathrm{C}$ ( $45 \mathrm{~min}$ of process time), down to the lowest level of $10.1 \mu \mathrm{g} / \mathrm{mL}$. Since then, the DPPH antioxidant activity collapsed exponentially, with the respective IC50 level rising to about $351 \mu \mathrm{g} / \mathrm{mL}$ at the temperature of $67.5^{\circ} \mathrm{C}$ ( $90 \mathrm{~min}$ of process time). Based on Figure 3a, the evolution of the DPPH antioxidant activity seemed to reflect the TPC trend up to the temperature of $47^{\circ} \mathrm{C}$, then it decoupled from the latter at higher temperatures. No relationships arose with the flavonoids concentration shown in Figure $3 b$.

In SFN_T2 (Table 2), the DPPH assay showed a relatively low value of the IC50 level after just 5 min of process time, followed by a moderate decrease (increase of antioxidant activity), but only up to the temperature of $37.5^{\circ} \mathrm{C}$. During the isothermal step at the temperature of $43^{\circ} \mathrm{C}$, a further decrease of the IC50 level occurred during the first $15 \mathrm{~min}$, later stabilizing below $15 \mu \mathrm{g} / \mathrm{mL}$. Based on Figure $3 \mathrm{a}, \mathrm{b}$, the evolution of the DPPH antioxidant activity did not seem to reflect strictly either the TPC or TFC trends, beyond the fact that all three quantities showed a sustained increase (except for DPPH's IC50 level during the latter part of the process). 
As a preliminary conclusion, the DPPH antioxidant activity was extremely sensitive to the temperature level, with a sudden drop beyond $47^{\circ} \mathrm{C}$. It benefitted from both heating and, likely even more, cavitation time at lower temperatures.

Moreover, the concentration of total phenolics showed a moderate correlation with the DPPH antioxidant activity, which is not simple to elucidate. Some authors claimed that phenolic compounds are not the only factors responsible for the antioxidant activity, with other phytochemicals (e.g., carotenoids, terpenes, reducing carbohydrates, and essential oils) potentially affecting the total antioxidant activity. As well, other factors could affect the antioxidant properties of a compound, such as possible synergistic and antagonistic effects among additional components, interactions between the physical environment of the sample and the phenolic compounds, or the activity of specific phenolic compounds that were not suitably determined [42]. Anyway, based on the comparison of the results shown in Figure 3, Tables 1 and 2, the concentration of total phenolics could positively contribute to the small, yet significant, difference in the highest levels of the DPPH antioxidant activity (lowest IC50), occurring in both tests after 45 min of process time.

The evolution of the ORAC antioxidant activity looks very different from DPPH. In SFN_T1 (Table 1), the ORAC assay showed practically stable levels from 15 to $45 \mathrm{~min}$ of process time (temperature increase from 33 to $47^{\circ} \mathrm{C}$ ). Then, a remarkable growth was observed up to $75 \mathrm{~min}$ of process time (temperature of $61.5^{\circ} \mathrm{C}$ ), followed by a sharp drop in the latter $15 \mathrm{~min}$ of process time (up to the temperature of $67.5^{\circ} \mathrm{C}$ ). Based on Figure $3 \mathrm{a}, \mathrm{b}$, the evolution of the ORAC antioxidant activity did not reflect the TPC, nor the TFC trends.

In SFN_T2 (Table 2), the ORAC assay showed stable levels from 5 to $15 \mathrm{~min}$ of process time (temperature increase from 33 to $37.5^{\circ} \mathrm{C}$ ), followed by a sharp increase (more than doubling) in the next $15 \mathrm{~min}$ (up to the temperature of $43^{\circ} \mathrm{C}$ ). Then, in the isothermal step at the temperature of $43{ }^{\circ} \mathrm{C}$, a further remarkable growth of the antioxidant activity occurred, with no apparent peak. At the end of the process, the level of the ORAC antioxidant activity was much greater than the peak level observed in SFN_T1 (about 840 vs. $585 \mu \mathrm{MTE} / \mathrm{L}$ ). Based on Figure 3a,b, the evolution of the ORAC antioxidant activity showed correlation with both TPC and TFC, especially for temperatures levels higher than $37^{\circ} \mathrm{C}$, with exponential functions accurately fitting both relationships $\left(\mathrm{R}^{2}>0.92\right)$.

The preliminary conclusion can be drawn, that ORAC levels were very sensitive to the temperature, yet differently from DPPH. Indeed, ORAC levels increased with temperature in the approximate range 40 to $60{ }^{\circ} \mathrm{C}$, suddenly dropping with further heating. The ORAC levels also showed a stronger increase with cavitation time at the temperature of $43^{\circ} \mathrm{C}$; the investigation of such dependence on cavitation time at other temperature levels in the aforementioned range should be a subject for further research. Moreover, limited to SFN_T2, the concentration of total phenolics and total flavonoids showed accurate correlations with the ORAC levels, in the temperature range 31.5 to $43^{\circ} \mathrm{C}$, as well as during the isothermal step at the latter temperature level.

\subsection{Stability}

Aimed at assessing the time stability of the silver fir needles aqueous solutions, the TPC, TFC, DPPH, and ORAC levels were measured again, for both tests SFN_T1 and SFN_T2, 47 days and eight days later, respectively. Although other choices would have been possible, the samples collected after $60 \mathrm{~min}$ of process time, in each test, were selected for the stability assessment, because they corresponded to the maximum antioxidant activity, both DPPH and ORAC, in SFN_T2; the second peak level of the ORAC, and moderate DPPH in SFN_T1. Moreover, those samples shared the same process time. It is recalled that the operational temperatures after $60 \mathrm{~min}$ of process time were $54^{\circ} \mathrm{C}$ in SFN_T1, and $43{ }^{\circ} \mathrm{C}$ in SFN_T2.

Table 3 shows the antioxidant activities, according to the DPPH and ORAC assays, observed at different times after the tests SFN_T1 and SFN_T2. 
Table 3. TPC, TFC, DPPH (IC50), and ORAC levels, with the respective standard deviations, measured at different times after tests SFN_T1 and SFN_T2. Data refer to samples collected after 60 min of process time in each test. Superscripts indicate indistinguishable values $(p>0.05)$. Difference expressed as \% change compared to the initial value.

\begin{tabular}{ccccccc}
\hline & \multicolumn{5}{c}{ SFN_T1 } & \multicolumn{3}{c}{ SFN_T2 } \\
\cline { 2 - 6 } & Day 1 & Day 48 & Diff. & Day 1 & Day 9 & Diff. \\
\hline $\begin{array}{c}\text { TPC } \\
(\mathrm{mgGAE} / \mathrm{mL})\end{array}$ & $0.103 \pm 0.002$ & $0.053 \pm 0.007$ & $-48 \%$ & $0.131 \pm 0.002$ & $0.091 \pm 0.003$ & $-31 \%$ \\
\hline $\begin{array}{c}\text { TFC } \\
(\mathrm{mgCE} / \mathrm{mL})\end{array}$ & $0.363 \pm 0.002$ & $0.209 \pm 0.004$ & $-42 \%$ & $0.432 \pm 0.001$ & $0.309 \pm 0.002$ & $-28 \%$ \\
\hline $\begin{array}{c}\text { DPPH } \\
(\mathrm{IC50}, \mu \mathrm{g} / \mathrm{mL})\end{array}$ & $44.0 \pm 2.1$ & $65.8 \pm 3.0$ & $50 \%$ & $14.7 \pm 0.8^{\mathrm{a}}$ & $14.4 \pm 1.0^{\mathrm{a}}$ & $0 \%$ \\
\hline $\begin{array}{c}\text { ORAC } \\
(\mu \mathrm{MTE} / \mathrm{L})\end{array}$ & $457.9 \pm 24.1$ & $128.3 \pm 8.5$ & $-72 \%$ & $840.8 \pm 31.4$ & $152.3 \pm 5.7$ & $-82 \%$ \\
\hline
\end{tabular}

The total phenolic content (TPC); The total flavonoids content (TFC); Diff.: Difference.

With regard to the antioxidant activity, two striking and contrasting features arose. The antioxidant activity measured by the ORAC assay decreased to less than $30 \%$ of its level in day 1 in SFN_T1, and to less than 20\% in SFN_T2, despite the shorter time lapse between the observations in the latter case. The IC50 dose for the DPPH assay increased by 50\% compared to its level in day 1 in SFN_T1 and did not change in SFN_T2.

As mentioned in Section 2.3.3, the DPPH assay is specific for the estimation of the antioxidant activity of plant extracts and is related to activity against lipid oxidation. As mentioned in Section 2.3.4, the ORAC assay is more specific for human plasma, and measures the scavenging of peroxyl as well as of hydroxyl radicals.

Based on the above, the aqueous extracts produced by means of the hydrodynamic cavitation process, absent any preservative additives, fully retained the antioxidant activity towards lipid oxidation, at least up to nine days after processing, and its decay is relatively moderate even after 48 days. Conversely, the ability to scavenge peroxyl and hydroxyl radicals dropped very quickly, though it was still observable after 48 days.

With regard to total phenolics and total flavonoids, the results are relatively uniform across the two tests, showing comparable relative drops in the respective concentrations, once the different time lapses are considered, as well as a continuous decay in time after samples production. Apparently, the $\mathrm{HC}$ process did dot damage or denature the compounds responsible for the DPPH antioxidant activity, either polyphenols, flavonoids, or others, such as essential oils, at the condition of limiting the process temperatures, a safe level for the latter being somewhere between 43 and $47^{\circ} \mathrm{C}$.

\section{Discussion}

The observed levels of the in vitro antioxidant activity of the samples extracted during the performed tests highlight the very good potential of the HC process for the creation of aqueous solutions, endowed with bioactive compounds extracted from silver fir needles. In test SFN_T1, the activity towards DPPH radicals, measured the day after the test (Table 1), achieved the lowest level of the respective IC50 (highest antioxidant activity) of about $10 \mu \mathrm{g} / \mathrm{mL}$, while, in SFN_T2, the lowest level was about $14 \mu \mathrm{g} / \mathrm{mL}$ (Table 2), both after $45 \mathrm{~min}$ of process time.

Table 4 shows the highest level obtained for the DPPH antioxidant activity, throughout the tests carried out under this study, compared with results for few reference substances, including a synthetic antioxidant, and vitamin E, catechin, two essential oils, one of which extracted from Abies alba twigs and needles, and aqueous extracts from coniferous trees. Despite the relatively wide variability in the published levels of DPPH IC50, even for the same reference substances [45], the respective lowest level of DPPH IC50, achieved in the performed HC-driven tests, competed even with the lower values 
reported for ascorbic acid, quercetin, and catechin. It was also significantly lower than any other results, including the considered synthetic antioxidant, the essential oils, and other extracts.

Table 4. DPPH antioxidant activity: the highest level (lowest IC50) found in this study, and levels found for other substances. Where available, the respective standard deviations are indicated.

\begin{tabular}{|c|c|c|}
\hline Substance & DPPH (IC50, $\mu \mathrm{g} / \mathrm{mL})$ & Ref. \\
\hline Abies alba needles extract & $10.1 \pm 0.4$ & This study ${ }^{a}$ \\
\hline Ascorbic acid (reference substance) & 5.85 & {$[45]$} \\
\hline Ascorbic acid (reference substance) & 7.62 & [12] \\
\hline Ascorbic acid (reference substance) & $20 \pm 1.3$ & [44] \\
\hline Ascorbic acid (reference substance) & 50 & [45] \\
\hline Resveratrol (reference substance) & 16.62 & [12] \\
\hline Quercetin (reference substance) & $10.5 \pm 4.6$ & [46] \\
\hline $\begin{array}{l}\text { Butylated hydroxytoluene } \\
\text { (synthetic antioxidant, reference substance) }\end{array}$ & 11.58 & [12] \\
\hline $\begin{array}{l}\text { Butylated hydroxytoluene } \\
\text { (synthetic antioxidant, reference substance) }\end{array}$ & 21.30 & [45] \\
\hline$\alpha$-Tocopherol (vitamin E) & 27.1 & [45] \\
\hline Epigalocatechin gallate (a type of catechin) & 7.06 & [12] \\
\hline Abies alba twigs and needles (essential oil) & $27 \pm 6.3$ & [44] \\
\hline Clove (essential oil) & $13.2 \pm 2.9$ & [46] \\
\hline Abies alba wood (extract) & 35.46 & [12] \\
\hline Pinus coulteri needles (extract) ${ }^{b}$ & $22.7 \pm 0.6$ & [47] \\
\hline Pinus densiflora needles (extract) ${ }^{\mathrm{c}}$ & 270 & [48] \\
\hline
\end{tabular}

${ }^{a}$ Lowest level of DPPH IC50 observed throughout the tests. ${ }^{b}$ Crude extract. ${ }^{c}$ Hot water extract.

The ORAC antioxidant activity levels for the aqueous solutions obtained in this study, from HC processing of Abies alba needles, were hard to compare with data obtained from other studies, due to scarce literature. In particular, very few data exist about the ORAC levels of aqueous solutions, such as beverages, while plenty of data are available, referred to the unit mass of several functional substances.

However, at least one quite comprehensive study investigated the ORAC levels of several commercial beverages available on the U.S. market, also in relation with the respective total phenol concentration [49]. That is especially interesting, due to the observed strict relationship between the aforementioned quantities for the SFN_T2 test, where the highest ORAC level was achieved.

Table 5 shows the ORAC and TPC levels for three representative samples extracted from SFN_T2, as well as for most of the commercial beverages investigated in [49]. Despite all the ORAC levels for those beverages were higher than the levels achieved in this study, the ratios between the respective levels for ORAC and TPC were relatively similar.

Table 5. ORAC antioxidant activity and TPC levels, with the respective standard deviations, from this study, and from a previous study (the TPC levels were referred to the volume of $1 \mathrm{~L}$ ).

\begin{tabular}{cccc}
\hline Substance & ORAC $(\boldsymbol{\mu M T E} / \mathbf{L})$ & TPC $(\mathbf{m g G A E} / \mathbf{L})$ & Ref. \\
\hline Abies alba needles extract & $186.6 \pm 18.1$ & $74 \pm 4$ & This study $^{\mathrm{a}}$ \\
Abies alba needles extract & $497.9 \pm 22.8$ & $108 \pm 2$ & This study $^{\mathrm{b}}$ \\
Abies alba needles extract & $840.8 \pm 31.4$ & $131 \pm 2$ & This study $^{\mathrm{c}}$ \\
\hline Iced white tea & $2700 \pm 300$ & $900 \pm 0$ & \\
Iced black tea & $3100 \pm 200$ & $400 \pm 0$ & \\
Apple juice & $4800 \pm 1000$ & $400 \pm 100$ & \\
Iced green tea & $5300 \pm 1900$ & $800 \pm 100$ & \\
Orange juice & $7400 \pm 500$ & $700 \pm 100$ & \\
Cranberry juice & $15,400 \pm 2100$ & $1700 \pm 200$ & \\
Blueberry juice & $20,600 \pm 2900$ & $2300 \pm 400$ & \\
Red wine & $25,700 \pm 2100$ & $3500 \pm 100$ & \\
\hline
\end{tabular}

a 15 min of process time. ${ }^{b} 45$ min of process time. ${ }^{c} 60$ min of process time. 
Figure 4 shows the ORAC to TPC ratios, computed from data shown in Table 5, including the propagation of the respective uncertainties. These data tell an interesting story, with key points summarized as follows:

- The ORAC to TPC levels found in this study increased with cavitation time, with the SFN_T2 sample collected after 60 min exhibiting both the highest ORAC level and the highest ORAC to TPC level, which could suggest the HC ability to extract more and more functional polyphenols, likely bound in the raw material, during the process.

- The highest ORAC to TPC level found in this study was comparable with most of the respective levels found for the considered commercial beverages, and it is likely to increase further with longer and/or optimized cavitation process.

- The ORAC levels achieved in this study are likely to increase also after increasing the concentration of the raw material added to water, which was very low in this study; however, the dose-dependency over the ORAC antioxidant activity needs specific investigation.

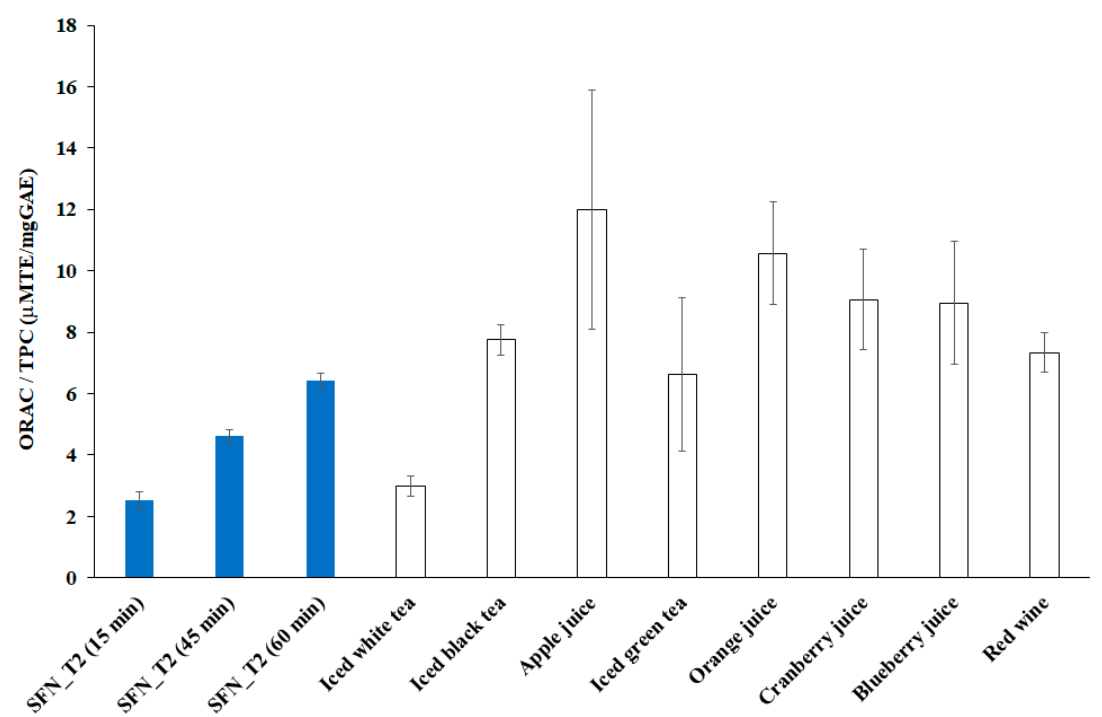

Figure 4. ORAC (The oxygen radical absorbance capacity) to TPC (The total phenolic content) ratios for three samples from the test SFN_T2 (this study) and referred to few commercial beverages.

Thus, interesting perspectives exist about obtaining aqueous solutions, based on silver fir needles as raw material, and manufactured by means of the HC method proposed in this study, endowed with high ORAC levels. The above considerations also lead to recommending further research on the relationship between the ORAC antioxidant activity and the functional compounds extracted in the aqueous solution.

Based on the nature of the raw material, the structural and operational features of the performed processes, and the obtained results, it is safe to state that the HC technique and the related method, proposed in this study, adhere to the nowadays well-established six principles of green extraction [50]:

(1) Innovation by selection of varieties and use of renewable plant resources: Abies alba Mill. is a plant species at risk in Italian northern Apennines, relict of past large populations [51]; moreover, fir needles are abundant and renewable by-products of forest management, and can be used in small proportion to achieve remarkable oxidant activity in aqueous solution.

(2) Use of alternative solvents and principally water or agro-solvents: water was the only solvent used in the discussed extraction method.

(3) Reduce energy consumption by energy recovery and using innovative technologies: as little as $0.04 \mathrm{kWh}$ of electricity per liter of aqueous solution were consumed during $60 \mathrm{~min}$ of process time in both tests discussed in this study, with no other energy source used during operation; electricity consumed for centrifuge separation was not accounted for, but it was assumed negligible. 
(4) Production of co-products instead of waste to include the bio- and agro-refining industry: once deprived of soluble (and solubilized) compounds, the residual fraction of the original mass of fir needle, which had to be separated from the aqueous solution, could be destined to composting, anaerobic digestion, or even to reuse as feedstock for biochar [52].

(5) Reduce unit operations and favor safe, robust and controlled processes: the discussed extraction method comprised only two operations after fir needles harvesting, i.e., HC processing, and mechanical separation; the equipment was simple, safe, robust, and easily controllable; the HC process needed to achieve high levels of the antioxidant activity was very fast (60 min or less).

(6) Aim for a non-denatured and biodegradable extract without contaminants: absent any additives, water and fir needles were the only ingredients; although indirectly inferred, as discussed in Section 3.4, the HC process did not denature the antioxidant compounds of silver fir needles.

\section{Conclusions}

The results discussed in this study appeared to meet the best expectations raised by other emerging and successful HC applications. Indeed, HC processing of silver fir needles, as single unit operation, was proven to boost the antioxidant activity of the resulting aqueous extract, without the use of any solvent other than water, by means of a very fast process, especially considering the very small concentration of the raw material $(0.44 \% w / w$ dry basis).

This study could open a new field of application for controlled HC processes, with potential for practical developments, due to high efficacy, energy and resource use efficiency, as well as straightforward scalability. These properties were the main drivers of several recent and successful implementations of $\mathrm{HC}$ processes at the pilot and industrial scale, e.g., in the fields of water heating [53], beer-brewing [20,22], wastewater remediation [27], pretreatment of biomasses [54], and enhancement of biochar properties [36]. The same properties were considered essential for bridging the gap from the pilot to the industrial scale in the food field, such as in the extraction of bioactive compounds [18,55], including from fruits [56], and cereals [57], as well as in food pasteurization and sterilization [18,58], and in the creation of stable oil-in-water nanoemulsions [18].

HC processes could lead to boost the efficacy of Abies alba needles in the applications described in Appendix B, as well as to extend the respective use in other fields, such as preserving and health-promoting additives in beer. However, much research remains to be done.

The DPPH antioxidant activity of aqueous solutions was shown to be remarkably dependent on solution $\mathrm{pH}$ (higher in less acidic media), and on the nature and concentration of metal ions [39]. A similar dependence can be expected for silver fir needles water extracts, including dependence on the properties of further liquids in which it should be diluted (e.g., in the case of fortification of mineral waters or other beverages, including alcoholic ones). Further research along this direction is therefore recommended. As well, the dose-dependency of the aqueous solution properties should be investigated (only one concentration level was used in this study).

As pointed out in Section 3.4., it is likely that ORAC-related compounds are much more unstable in time than DPPH-related compounds; more generally, the relationship between antioxidant activity, either DPPH or ORAC, and the functional compounds extracted from silver fir needles, needs further investigation. Such recommendation has already been suggested, limited to the ORAC antioxidant activity, in relation to the results shown in Figure 4. Thus, further research is urged, about the accurate, quantitative analysis of the composition of the aqueous solutions, e.g., polyphenols, flavonoids, and essential oils, extracted by means of the method proposed in this study.

Another direction for further research could concern the additivation of silver fir needles water extracts with preservative agents, such as citric acid or related formulations [59], aimed at the stabilization in time of the antioxidant activity. The additivation with pectin from natural sources could also be useful, due to its emulsifying properties, potentially leading to stable encapsulation of 
essential oils [60]. As well, the investigation of the dependence of the stability on the water properties is recommended.

More generally, only silver fir (Abies alba Mill.) needles were processed for the purpose of this study. Whether hydrodynamic cavitation could be successfully applied to other plant raw materials, however likely it may be, should be proven by suitable experiments, thus suggesting another direction for further research.

Last, in this study, both DPPH and ORAC antioxidant activities were measured in vitro. Further research should address the in vivo effectivity of the aqueous solutions of fir needles, produced by means of HC processes, e.g., towards the prevention of lipid oxidation in storage foods, stimulation of plant growth, and fortification of beverages, the latter along with the investigation of the effects on the human health, including the bioavailability issue. In this regard, innovative assays could be considered, to measure the antioxidant activity of food extracts, based on the generation of physiological radical species [61].

Author Contributions: Conceptualization, F.M. and F.Z.; Data curation, A.B., F.M. and F.Z.; Formal analysis, F.M.; Investigation, L.A., A.B., F.M. and F.Z.; Methodology, L.A., F.M. and F.Z.; Resources, L.A., L.P.D. and F.M.; Software, A.B. and F.M.; Supervision, L.P.D., F.M. and F.Z.; Validation, A.B., L.P.D. and F.M.; Visualization, F.M.; Writing-original draft, A.B., F.M. and F.Z.; Writing-review \& editing, L.A., A.B., L.P.D., F.M. and F.Z.

Acknowledgments: Companies BYSEA S.r.l. and GBL S.r.l. (Italy) are gratefully acknowledged for their technical support in part of the tests; the authors thank A. Raschi (CNR-IBIMET) for the continuous support and the provision of internal resources; R. Meneguzzo is acknowledged for the identification of the silver fir trees and his support in the collection of test materials.

Conflicts of Interest: The authors declare no conflict of interest.

\section{Appendix A}

The large variability observed in the bioactive properties of extracts from Abies alba can be ascribed to the corresponding variability of the compounds and chemical properties, in turn related to the collection period, the stage of growth, the geographical location, the environmental conditions and ecological factors, as well as to the genetic diversity. For example, silver firs growing in Southern Europe revealed higher genetic diversity than other European regions [11].

The composition of essential oils (EOs) extracted from silver fir needles exhibits a remarkable variability through the growing regions, environmental conditions, plant age and season, as well as genetic variability. Table A1 shows the range of concentrations of the main constituents of the EOs, drawn from few studies [44,62-64]; based on the same studies, EOs represent between 0.77 and $0.92 \%$ $w / w$ (dry matter) of silver fir needles total biomass.

Although most of EOs constituents show bioactive properties, limonene (PubChem CID: 440917), a monoterpene, was likely the most studied. Limonene is endowed with a wide-spectrum of antimicrobial, anti-oxidant, and anti-inflammatory properties, finding countless applications in the cosmetic and food industries, in the latter ones for both nutraceutical and anti-spoiling purposes [65].

It was first used in the 1950s as a bio-solvent, alternative to solvents derived from fossil fuels, as well as an insecticide, and two decades later as an antibacterial [66]. In the early 1990s, its plant antifungal and antibacterial properties were first identified [67], and further scientific insight about the use of limonene as a bio-pesticide was supplied starting in the mid-2000s [68]. At the same time, limonene was proved to be an effective adjuvant in preventive therapies against asthma [69].

It is worth noting that the antimicrobial action of limonene was found to markedly increase when applied as an oil-in-water nanoemulsion, for example reducing the thermal resistance of Listeria monocytogenes by 100 times, against only two to five times when added directly [70]. On the other hand, EOs from different raw materials are volatile under environmental conditions; in particular, limonene is chemically unstable in the presence of air, light, moisture, and high temperatures, hindering the respective application as flavorings in the food industry and affecting the shelf-life. The same holds for EOs applications as biopesticides, due to rapid oxidative degradation and evaporation in the open 
environment, leading to the need for high application rate, and stimulating research on the respective encapsulation allowing controlled and prolonged release [71].

Table A1. Range of concentrations of the main constituents of EOs for needles of silver fir (Abies alba Mill.), expressed as $\% w / w$ of total essential oils (Eos) dry mass.

\begin{tabular}{cc}
\hline Essential Oils & Range of Concentration \\
\hline$\beta$-Pinene ${ }^{1}$ & $0.51-32.80 \%$ \\
Bornyl acetate $^{1}$ & $4.40-30.31 \%$ \\
delta-3-Carene $^{1}$ & $13.85 \%{ }^{3}$ \\
Camphene $^{1}$ & $6.90-19.91 \%$ \\
Limonene $^{1}$ & $6.10-13.90 \%$ \\
$\alpha^{\alpha-P i n e n e^{1}}$ & $2.87-17.30 \%$ \\
Tricyclene $^{1}$ & $0.80-12.90 \%$ \\
$\beta$-Caryophyllene & \\
$^{2}$ & $1.30-6.70 \%$ \\
-Humulene $^{2}$ & $0.20-3.80 \%$ \\
-Phellandrene & $0.00-4.90 \%$ \\
Santene $^{2}$ & $1.20-2.00 \%$ \\
Myrcene $^{1}$ & $0.80-1.00 \%$ \\
Terpinolene $^{1}$ & $0.30-1.10 \%$ \\
Sabinene $^{1}$ & $0.10 \%{ }^{1}$ \\
\hline
\end{tabular}

Based on the aforementioned shortfalls, methods have been proposed to reduce volatility and control the release of such compounds. For example, a recent study suggested nanoencapsulation of limonene in oil-in-water nanoemulsions created by means of ultrasonic irradiation, sustaining cavitation processes, and stabilized with a mixture of pectin and whey proteins [72].

\section{Appendix B}

Essential oil extracted by steam distillation from needles and twigs of Abies alba plants in Korea showed strong activities against DPPH and ABTS radicals, while only little antibacterial properties [44]. In particular, the concentration required for 50\% reduction against DPPH radicals was measured at the level of $27 \pm 6.3 \mu \mathrm{g} / \mathrm{mL}$, statistically indistinguishable from ascorbic acid $(20 \pm 1.3 \mu \mathrm{g} / \mathrm{mL})$, slightly lower (higher activity) than for butylated hydroxyanisole, and much lower than for butylated hydroxytoluene, which are reference substances; such strong activity was attributed mainly to limonene (7.5\% of total essential oil). Moreover, a mild antibacterial activity was observed against Staphylococcus aureus (Gram-positive bacteria), and insignificant activity against Gram-negative bacteria such as Acinetobacter baumannii, Escherichia coli, Vibrio parahaemolyticcus, as well as against Gram-positive bacteria such as Streptococcus mutans and Listeria monocytogenes.

In a recent study, 21 plant-extracted essential oils were tested with regards to their antibacterial activity, i.e., growth inhibition of pathogenic and spoilage species of Pseudomonas spp., and antioxidant activity, on samples of freshwater fish [64]. In contrast to previous results, Abies alba essential oil, extracted from the respective needles, showed the highest antibacterial activity (lowest inhibitory concentration) towards few bacterial species; however, its antioxidant activity, measured by the DPPH assay, was the smallest over the considered essential oils.

The results from the latter two studies suggest that the level of antioxidant activity could be related to the specific composition of the Abies alba essential oils (for example, limonene was not even detected in the latter study), while the antibacterial activity is strongly dependent also on the considered bacterial strain. The analysis of the antimicrobial activity of essential oils extracted by hydrodistillation from twigs and needles of nine Abies species in Turkey, including Abies alba Mill., confirmed the strong dependence on both the source of essential oils and the microorganism strain [73]. While, overall, Abies alba showed a moderate activity, no essential oils acted against Escherichia Coli; as well, the activity was higher against yeast strains than against bacteria. 
The aqueous preparations from different parts of Abies alba, and its mistletoe Viscum album se abies, exhibited antiproliferative effects on the malignant L-1210 cell line, and anticarcinogenic effects on rats treated with benzo $(\alpha)$ pyrene, significantly reducing the tumour growth and prolonging their life [74]. The antiproliferative effects were attributed, among the others, to the monoterpenes contained in Abies alba. The raw materials, among which different parts of Abies alba, were extracted in tap water by successive boiling and condensations, according to a patented technique.

Aqueous extracts from bark of silver fir in Slovenia were tested for in vitro antioxidant activity towards DPPH radicals, in a comparative study with analogous extracts from maritime pine [75]. Silver fir extracts showed $91 \%$ higher activity than the ones from maritime pine; such result was attributed to as much as 13 natural antioxidant compounds, comprising essential oils, flavonoids, and lignans. In a more recent study carried out by the same research group in Slovenia, a dried aqueous extract based on wood from branches of silver fir plants was analysed in terms of its in vitro antioxidant activity measured according to a few assays, among which DPPH, as well as the scavenging of the powerful, broad spectrum hydroxyl radicals $(\cdot \mathrm{OH})$ [12]. While the DPPH assay showed lower activity in comparison to a few well-known antioxidant molecules, such as ascorbic acid and resveratrol, and, coherently, lower inhibitory activity against lipid peroxidation, the $\cdot \mathrm{OH}$ radical scavenging activity showed comparatively much higher levels than all other considered substances. Most of the antioxidant activity was attributed to lignans, and found to occur as well in vivo, lowering the glycaemic response, and contributing to control the blood glucose levels, thus showing a high bioactive potential.

Higher in vitro antioxidant activity towards hydroxyl radicals, in comparison with few reference substances, such as resveratrol, Butylated hydroxytoluene, vitamin E, and epigallocatechin gallate, was shown for aqueous extracts of silver fir trunk [76]. Moreover, the same aqueous extracts, added to an atherogenic diet of guinea pigs, improved the relaxation response and prevented the development of atherosclerotic plaques in aorta, thus confirming an important bioactivity. In a more recent study from the same research group, an aqueous extract of silver fir trunk dose-dependently reduced ischemic-reperfusion heart damage in rats [77]. As an important conclusion, the whole extract performed much better than its single constituents, suggesting a synergetic effect of multiple bioactive compounds.

In a recent study, silver fir wood and bark extracts were shown powerful activity in controlling blood glucose level, by means of the effective inhibition of specific enzymes, such as $\alpha$-glucosidase, $\alpha$-amylase, and dipeptidyl peptidase 4 , mainly attributed to lignans, as well as by means of the extracts antioxidant activity [78]. In addition, due to the higher effect in comparison with non-coniferous sweet chestnut wood extract, and standardized maritime pine bark extract, those results supported the use of the considered silver fir extracts as food supplements and functional foods aimed at preventing diabetes diseases. Another important finding concerned the dose-dependency of the blood glucose regulatory effect, which was remarkably non-linear, with a rather puzzling, yet significant, dropping of the efficiency at high extract concentrations.

Recently, specific triterpenes extracted from the mature bark of Abies procera, a species widespread in western North America, were tested against two flatworm parasites, responsible for fasciolosis and schistosomiasis, two endemic tropical diseases affecting both cattle and sheep, and humans [79]. Especially one of such triterpenes revealed a potent and selective anthelmintic activity, opening the way to further research into effective drugs.

Synthetic phenolic antioxidants were reported to produce negative effects on human health, when used as food additives to prevent lipid oxidation processes, thereby stimulating the search for natural antioxidant products [80]. The observation of the antioxidant and antimicrobial activity of extracts from needles, and other parts, of coniferous trees led to the respective application to food preservation, with particular reference to the prevention of lipid peroxidation, and microbiological safety. In particular, extracts of fir needles and twigs from several Abies species, such as Abies alba Mill., Abies sibirica Ledeb., Abies sachalinensis Masters, Abies mayriana Miyabe et Kudo, and Abies balsamea (L.) Mill., were recently suggested for their use as natural antioxidants for poultry and meat products in 
the U.S. [81]. While the respective antioxidant activity could be ascribed to essential oils (terpenes), and flavonoids, extracts from the aforementioned products should be labelled as 'natural flavouring' or the like.

In a real-scale experiment, broiler chicken thigh muscles produced by a poultry station were dipped in a solution of essential oil extracted from Abies alba, in concentrations of 0.1 and $0.2 \% v / w$, in order to investigate the respective oxidative stability during chilling storage [82]. The observed lipid oxidation up to 16 days of storage was significantly lower in comparison with not only air-packaged control samples, but also with vacuum-packaged samples, and vacuum-packaged samples treated with a well-known synthetic preservative substance. The dependence on concentration was mild, so much that the respective results were statistically indistinguishable.

A commercial extract from Abies Sibirica $(1 \% v / v)$ was tested for the control of storage decay of strawberry (development of grey mould, Rhizopus rot, and blue mould), in comparison with various chitosan formulations and other synthetic and natural resistance inducers [83]. The Abies Sibirica extract showed good antimicrobial activity, attributed to its triterpene acids, generally comparable to the other substances.

A decade before the latter study, the triterpene acids themselves, again extracted from Abies Sibirica, and in particular from its needles, showed significant and remarkable in vitro and in vivo plant-growth regulator activity, leading to accelerated and increased sprouting of wheat seeds, as well as stimulating the growth of roots and shoots [84]. The extraction of triterpenes in water-soluble form was carried out by means of a mechanochemical method, that has been widely applied since the 1990s, including needles' drying, grinding, and centrifugation, followed by the use of ether as a solvent, along with other chemicals.

\section{References}

1. Hulme, N. Libellus de Natura, Causa, Curationeque Scorbuti. To Which is Annexed a Proposal for Preventing the Scurvy in the British Navy. Available online: https://books.google.com.hk/books?hl= zh-TW\&lr=\&id=V0ZcAAAAcAAJ\&oi=fnd\&pg=PA3\&dq=Libellus+de+Natura, + Causa, + Curationeque+ Scorbuti.+To+Which+is+Annexed+a+Proposal+for+Preventing+the+Scurvy+in+the+British+Navy\& ots=-ZMCqtHPGT\&sig=iTO1EEITqyp-JDQU0VidxBgSKlc\&redir_esc=y\#v=onepage\&q=Libellus $\% 20 \mathrm{de} \%$ 20Natura \%2C\%20Causa\%2C\%20Curationeque\%20Scorbuti.\%20To\%20Which\%20is\%20Annexed \%20a\% 20Proposal\%20for\%20Preventing $\% 20$ the $\% 20$ Scurvy $\% 20 \mathrm{in} \% 20$ the $\% 20$ British $\% 20$ Navy \&f fffalse (accessed on 10 December 2018).

2. Lind, J. A Treatise of the Scurvy; Sands, Murray, and Cochran: Edinburgh, UK, 1753.

3. Smith, A.H. Beer and Scurvy. Some Notes From History. Lancet 1918, 192, 813-815. [CrossRef]

4. Charters, E. Disease, War, and the Imperial State: The Welfare of the British Armed Forces During the Seven Years' War; University of Chicago Press: Chicago, IL, USA, 2014; ISBN 978-0226180007.

5. Charters, E.M. Disease, Wilderness Warfare, and imperial relations: The battle for Quebec, 1759-1760. War Hist. 2009, 16, 1-24. [CrossRef]

6. Tešević, V.; Milosavljević, S.; Vajs, V.; Dordević, I.; Soković, M.; Lavadinović, V.; Novaković, M. Chemical composition and antifungal activity of the essential oil of Douglas fir (Pseudosuga menziesii Mirb. Franco) from Serbia. J. Serbian Chem. Soc. 2009, 74, 1035-1040. [CrossRef]

7. Stubbs, B.J. Captain Cook's beer: The antiscorbutic use of malt and beer in late 18th century sea voyages. Asia Pac. J. Clin. Nutr. 2003, 12, 129-137. [PubMed]

8. Kodicek, E.H.; Young, F.G. Captain Cook and Scurvy. Notes Rec. R. Soc. Lond. 1969, 24, 43-63. [CrossRef]

9. Laing, J. Medicine and surgeryin the Artic Circle. Edinb Med. J. 1901, 9, 449-451.

10. Friedemann, T.E.; Kraybill, H.F.; Consolazio, C.F. The uses of recommended dietary allowances in military nutrition. Am. J. Public Health 1959. [CrossRef]

11. Belletti, P.; Ferrazzini, D.; Ducci, F.; De Rogatis, A.; Mucciarelli, M. Genetic diversity of Italian populations of Abies alba. Dendrobiology 2017, 77, 147-159. [CrossRef] 
12. Tavčar Benković, E.; Žigon, D.; Mihailović, V.; Petelinc, T.; Jamnik, P.; Kreft, S. Identification, in vitro and in vivo Antioxidant Activity, and Gastrointestinal Stability of Lignans from Silver Fir (Abies alba) Wood Extract. J. Wood Chem. Technol. 2017, 37, 467-477. [CrossRef]

13. Sahin, H.; Yalcin, O. Chemical Composition and Utilization of Conifer Needles-A Review. J. Appl. Life Sci. Int. 2017, 14, 1-11. [CrossRef]

14. Yang, X.-W.; Li, S.-M.; Shen, Y.-H.; Zhang, W.-D. Phytochemical and Biological Studies ofAbies Species. Chem. Biodivers. 2008, 5, 56-81. [CrossRef] [PubMed]

15. Stalikas, C.D. Extraction, separation, and detection methods for phenolic acids and flavonoids. J. Sep. Sci. 2007, 30, 3268-3295. [CrossRef]

16. Brglez Mojzer, E.; Knez Hrnčič, M.; Škerget, M.; Knez, Ž.; Bren, U. Polyphenols: Extraction Methods, Antioxidative Action, Bioavailability and Anticarcinogenic Effects. Molecules 2016, 21, 901. [CrossRef] [PubMed]

17. Simpson, A.; Ranade, V.V. Modelling of hydrodynamic cavitation with orifice: Influence of different orifice designs. Chem. Eng. Res. Des. 2018, 136, 698-711. [CrossRef]

18. Carpenter, J.; Badve, M.; Rajoriya, S.; George, S.; Saharan, V.K.; Pandit, A.B. Hydrodynamic cavitation: An emerging technology for the intensification of various chemical and physical processes in a chemical process industry. Rev. Chem. Eng. 2017, 33, 433-468. [CrossRef]

19. Ciriminna, R.; Albanese, L.; Di Stefano, V.; Delisi, R.; Avellone, G.; Meneguzzo, F.; Pagliaro, M. Beer produced via hydrodynamic cavitation retains higher amounts of xanthohumol and other hops prenylflavonoids. LWT Food Sci. Technol. 2018, 91, 160-167. [CrossRef]

20. Albanese, L.; Ciriminna, R.; Meneguzzo, F.; Pagliaro, M. Beer-brewing powered by controlled hydrodynamic cavitation: Theory and real-scale experiments. J. Clean. Prod. 2017, 142, 1457-1470. [CrossRef]

21. Albanese, L.; Ciriminna, R.; Meneguzzo, F.; Pagliaro, M. Gluten reduction in beer by hydrodynamic cavitation assisted brewing of barley malts. LWT Food Sci. Technol. 2017, 82, 342-353. [CrossRef]

22. Albanese, L.; Ciriminna, R.; Meneguzzo, F.; Pagliaro, M. Innovative beer-brewing of typical, old and healthy wheat varieties to boost their spreading. J. Clean. Prod. 2018, 171, 297-311. [CrossRef]

23. Albanese, L.; Ciriminna, R.; Meneguzzo, F.; Pagliaro, M. Energy efficient inactivation of Saccharomyces cerevisiae via controlled hydrodynamic cavitation. Energy Sci. Eng. 2015, 3, 221-238. [CrossRef]

24. Gogate, P.R.; Pandit, A.B. Cavitation Generation and Usage Without Ultrasound: Hydrodynamic Cavitation. In Theoretical and Experimental Sonochemistry Involving Inorganic Systems; Pankaj, D.S., Ashokkumar, M., Eds.; Springer: Dordrecht, The Netherlands, 2011; pp. 69-106. ISBN 978-90-481-3886-9.

25. Yasui, K.; Tuziuti, T.; Sivakumar, M.; Iida, Y. Sonoluminescence. Appl. Spectrosc. Rev. 2004, 39, $399-436$. [CrossRef]

26. Pawar, S.K.; Mahulkar, A.V.; Pandit, A.B.; Roy, K.; Moholkar, V.S. Sonochemical effect induced by hydrodynamic cavitation: Comparison of venturi/orifice flow geometries. AIChE J. 2017, 63, 4705-4716. [CrossRef]

27. Ciriminna, R.; Albanese, L.; Meneguzzo, F.; Pagliaro, M. Wastewater remediation via controlled hydrocavitation. Environ. Rev. 2017, 25, 175-183. [CrossRef]

28. Ciriminna, R.; Albanese, L.; Meneguzzo, F.; Pagliaro, M. Hydrogen Peroxide: A Key Chemical for Today's Sustainable Development. ChemSusChem 2016, 9, 3374-3381. [CrossRef] [PubMed]

29. Yusaf, T.; Al-Juboori, R.A. Alternative methods of microorganism disruption for agricultural applications. Appl. Energy 2014, 114, 909-923. [CrossRef]

30. Yan, Y.; Thorpe, R.B. Flow regime transitions due to cavitation in the flow through an orifice. Int. J. Multiph. Flow 1990, 16, 1023-1045. [CrossRef]

31. Šarc, A.; Stepišnik-Perdih, T.; Petkovšek, M.; Dular, M. The issue of cavitation number value in studies of water treatment by hydrodynamic cavitation. Ultrason. Sonochem. 2017, 34, 51-59. [CrossRef]

32. Bagal, M.V.; Gogate, P.R. Wastewater treatment using hybrid treatment schemes based on cavitation and Fenton chemistry: A review. Ultrason. Sonochem. 2014, 21, 1-14. [CrossRef]

33. Gogate, P.R. Cavitation: An auxiliary technique in wastewater treatment schemes. Adv. Environ. Res. 2002, 6, 335-358. [CrossRef]

34. Bartolini, G.; Grifoni, D.; Magno, R.; Torrigiani, T.; Gozzini, B. Changes in temporal distribution of precipitation in a Mediterranean area (Tuscany, Italy) 1955-2013. Int. J. Climatol. 2018, 38, 1366-1374. [CrossRef] 
35. Costantini, E.; Fantappie, M.; L'Abate, G. Climate and Pedoclimate of Italy. In The Soils of Italy; Costantini, E., Dazzi, C., Eds.; Springer: Dordrecht, The Netherlands, 2013; p. 354, ISBN 9400756429.

36. Albanese, L.; Baronti, S.; Liguori, F.; Meneguzzo, F.; Barbaro, P.; Vaccari, F.P. Hydrodynamic cavitation as an energy efficient process to increase biochar surface area and porosity: A case study. J. Clean. Prod. 2019, 210, 159-169. [CrossRef]

37. Torti, S.D.; Dearing, M.D.; Kursar, T.A. Extraction of phenolic compounds from fresh leaves: A comparison of methods. J. Chem. Ecol. 1995, 21, 117-125. [CrossRef]

38. Talari, S.; Shyamsundarachary, R.; Srinivas, P.; Swamy, N.R. Quantification of total phenolic and total flavonoid contents in extracts of Oroxylum indicum L.Kurz. Asian J. Pharm. Clin. Res. 2012, 5, 177-179.

39. Pekal, A.; Pyrzynska, K. Effect of $\mathrm{pH}$ and metal ions on DPPH radical scavenging activity of tea. Int. J. Food Sci. Nutr. 2015, 66, 58-62. [CrossRef]

40. Kikuzaki, H.; Hisamoto, M.; Hirose, K.; Akiyama, K.; Taniguchi, H. Antioxidant properties of ferulic acid and its related compounds. J. Agric. Food Chem. 2002, 50, 2161-2168. [CrossRef]

41. Brand-Williams, W.; Cuvelier, M.E.; Berset, C. Use of a free radical method to evaluate antioxidant activity. LWT Food Sci. Technol. 1995, 28, 25-30. [CrossRef]

42. Craft, B.D.; Kerrihard, A.L.; Amarowicz, R.; Pegg, R.B. Phenol-Based Antioxidants and the In Vitro Methods Used for Their Assessment. Compr. Rev. Food Sci. Food Saf. 2012, 11, 148-173. [CrossRef]

43. Cao, G.; Prior, R.L. Comparison of different analytical methods for assessing total antioxidant capacity of human serum. Clin. Chem. 1998, 44, 1309-1315.

44. Yang, S.-A.; Jeon, S.-K.; Lee, E.-J.; Im, N.-K.; Jhee, K.-H.; Lee, S.-P.; Lee, I.-S. Radical Scavenging Activity of the Essential Oil of Silver Fir (Abies alba). J. Clin. Biochem. Nutr. 2009, 44, 253-259. [CrossRef]

45. Mishra, K.; Ojha, H.; Chaudhury, N.K. Estimation of antiradical properties of antioxidants using DPPH-Assay: A critical review and results. Food Chem. 2012, 130, 1036-1043. [CrossRef]

46. Pérez-Rosés, R.; Risco, E.; Vila, R.; Peñalver, P.; Cañigueral, S. Biological and Nonbiological Antioxidant Activity of Some Essential Oils. J. Agric. Food Chem. 2016, 64, 4716-4724. [CrossRef]

47. Merah, S.; Dahmane, D.; Krimat, S.; Metidji, H.; Nouasri, A.; Lamari, L.; Dob, T. Chemical analysis of phenolic compounds and determination of anti-oxidant, antimicrobial and cytotoxic activities of organic extracts of Pinus coulteri. Bangladesh J. Pharmacol. 2018, 13, 120. [CrossRef]

48. Park, Y.S.; Jeon, M.H.; Hwang, H.J.; Park, M.R.; Lee, S.H.; Kim, S.G.; Kim, M. Antioxidant activity and analysis of proanthocyanidins from pine (Pinus densiflora) needles. Nutr. Res. Pract. 2011, 5, 281-287. [CrossRef]

49. Seeram, N.P.; Aviram, M.; Zhang, Y.; Henning, S.M.; Feng, L.; Dreher, M.; Heber, D. Comparison of antioxidant potency of commonly consumed polyphenol-rich beverages in the United States. J. Agric. Food Chem. 2008, 56, 1415-1422. [CrossRef]

50. Chemat, F.; Vian, M.A.; Cravotto, G. Green extraction of natural products: Concept and principles. Int. J. Mol. Sci. 2012, 13, 8615-8627. [CrossRef]

51. Piovani, P.; Leonardi, S.; Piotti, A.; Menozzi, P. Conservation genetics of small relic populations of silver fir (Abies alba Mill.) in the northern Apennines. Plant Biosyst. 2010, 144, 683-691. [CrossRef]

52. Haider, G.; Steffens, D.; Moser, G.; Müller, C.; Kammann, C.I. Biochar reduced nitrate leaching and improved soil moisture content without yield improvements in a four-year field study. Agric. Ecosyst. Environ. 2015, 237, 80. [CrossRef]

53. Sun, X.; Kang, C.H.; Park, J.J.; Kim, H.S.; Om, A.S.; Yoon, J.Y. An experimental study on the thermal performance of a novel hydrodynamic cavitation reactor. Exp. Therm. Fluid Sci. 2018, 99, 200-210. [CrossRef]

54. Garuti, M.; Langone, M.; Fabbri, C.; Piccinini, S. Monitoring of full-scale hydrodynamic cavitation pretreatment in agricultural biogas plant. Bioresour. Technol. 2018, 247, 599-609. [CrossRef]

55. Cravotto, G.; Mariatti, F.; Gunjevic, V.; Secondo, M.; Villa, M.; Parolin, J.; Cavaglià, G. Pilot Scale Cavitational Reactors and Other Enabling Technologies to Design the Industrial Recovery of Polyphenols from Agro-Food By-Products, a Technical and Economical Overview. Foods 2018, 7, 130. [CrossRef]

56. Martynenko, A.; Astatkie, T.; Satanina, V. Novel hydrothermodynamic food processing technology. J. Food Eng. 2015, 152, 8-16. [CrossRef]

57. Lohani, U.C.; Muthukumarappan, K.; Meletharayil, G.H. Application of hydrodynamic cavitation to improve antioxidant activity in sorghum flour and apple pomace. Food Bioprod. Process. 2016, 100, 335-343. [CrossRef] 
58. Li, F.; Chen, G.; Zhang, B.; Fu, X. Current applications and new opportunities for the thermal and non-thermal processing technologies to generate berry product or extracts with high nutraceutical contents. Food Res. Int. 2017, 100, 19-30. [CrossRef]

59. Ciriminna, R.; Meneguzzo, F.; Delisi, R.; Pagliaro, M. Citric acid: Emerging Applications of a Key Biotechnology Industrial Product. Chem. Cent. J. 2017, 11, 1-9. [CrossRef]

60. Ciriminna, R.; Chavarría-Hernández, N.; Inés Rodríguez Hernández, A.; Pagliaro, M. Pectin: A new perspective from the biorefinery standpoint. Biofuels, Bioprod. Biorefining 2015, 9, 368-377. [CrossRef]

61. Soccio, M.; Laus, M.; Flagella, Z.; Pastore, D.; Soccio, M.; Laus, M.N.; Flagella, Z.; Pastore, D. Assessment of Antioxidant Capacity and Putative Healthy Effects of Natural Plant Products Using Soybean Lipoxygenase-Based Methods. An Overview. Molecules 2018, 23, 3244. [CrossRef]

62. Chalchat, J.C.; Sidibé, L.; Maksimovic, Z.A.; Petrovic, S.D.; Gorunovic, M.S. Essential oil of Abies alba mill., Pinaceae, from the pilot production in Montenegro. J. Essent. Oil Res. 2001, 13, 288-289. [CrossRef]

63. Zeneli, G.; Tsitsimpikou, C.; Petrakis, P.V.; Naxakis, G.; Habili, D.; Roussis, V. Foliar and cortex oleoresin variability of Silver fir (Abies alba Mill.) in Albania. Zeitschrift fur Naturforsch. Sect. C 2001, 56, 531-539. [CrossRef]

64. Kačániová, M.; Terentjeva, M.; Vukovic, N.; Puchalski, C.; Roychoudhury, S.; Kunová, S.; Klūga, A.; Tokár, M.; Kluz, M.; Ivanišová, E. The antioxidant and antimicrobial activity of essential oils against Pseudomonas spp. isolated from fish. Saudi Pharm. J. 2017, 25, 1108-1116. [CrossRef]

65. Fitzgerald, C.; Hossain, M.; Rai, D.K. Waste/By-Product Utilisations. In Innovative Technologies in Beverage Processing; Aguiló-Aguayoi, I., Plaza, L., Eds.; John Wiley \& Sons, Ltd.: Chichester, UK, 2017; pp. 297-309.

66. Ciriminna, R.; Lomeli-Rodriguez, M.; Demma Carà, P.; Lopez-Sanchez, J.A.; Pagliaro, M. Limonene: A versatile chemical of the bioeconomy. Chem. Commun. 2014, 50, 15288-15296. [CrossRef]

67. Singh, G.; Upadhyay, R.K.; Narayanan, C.S.; Padmkumari, K.P.; Rao, G.P. Chemical and fungitoxic investigations on the essential oil of Citrus sinensis (L.) Pers. J. Plant Dis. Prot. 1993, 100, 69-74.

68. Hollingsworth, R.G. Limonene, a Citrus Extract, for Control of Mealybugs and Scale Insects. J. Econ. Entomol. 2005, 98, 772-779. [CrossRef]

69. Keinan, E.; Alt, A.; Amir, G.; Bentur, L.; Bibi, H.; Shoseyov, D. Natural ozone scavenger prevents asthma in sensitized rats. Bioorganic Med. Chem. 2005, 13, 557-562. [CrossRef]

70. Maté, J.; Periago, P.M.; Palop, A. When nanoemulsified, d-limonene reduces Listeria monocytogenes heat resistance about one hundred times. Food Control 2016, 59, 824-828. [CrossRef]

71. Ciriminna, R.; Meneguzzo, F.; Pagliaro, M. Orange Oil. In Green Pesticides Handbook: Essential Oils for Pest Control; Nollet, L.M.L., Rathore, H.S., Eds.; CRC Press: Boca Raton, FL, USA, 2017; pp. 291-303, ISBN 978-1-49-875938-0.

72. Ghasemi, S.; Jafari, S.M.; Assadpour, E.; Khomeiri, M. Nanoencapsulation of D-limonene within nanocarriers produced by pectin-whey protein complexes. Food Hydrocoll. 2018, 77, 152-162. [CrossRef]

73. Bağci, E.; Diğrak, M. Antimicrobial activity of essential oils of some Abies (fir) species from Turkey. Flavour Fragr. J. 1996, 11, 251-256. [CrossRef]

74. Karkabounas, S.; Assimakopoulos, D.; Malamas, M.; Skaltsounis, A.L.; Leonce, S.; Zelovitis, J.; Stefanou, D.; Evangelou, A. Antiproliferative and anticarcinogenic effects of an aqueous preparation of Abies alba and Viscum album se abies, on a L-1210 malignant cell line and tumor-bearing Wistar rats. Anticancer Res. 2000, 20, 4391-4395.

75. Benković, E.T.; Grohar, T.; Žigon, D.; Švajger, U.; Janeš, D.; Kreft, S.; Štrukelj, B. Chemical composition of the silver fir (Abies alba) bark extract Abigenol ${ }^{\circledR}$ and its antioxidant activity. Ind. Crops Prod. 2014, 52, $23-28$. [CrossRef]

76. Drevenšek, G.; Lunder, M.; Benković, E.T.; Mikelj, A.; Štrukelj, B.; Kreft, S. Silver fir (Abies alba) trunk extract protects Guinea pig arteries from impaired functional responses and morphology due to an atherogenic diet. Phytomedicine 2015, 22, 856-861. [CrossRef]

77. Drevenšek, G.; Lunder, M.; Benković, E.T.; Štrukelj, B.; Kreft, S. Cardioprotective effects of silver fir (Abies alba) extract in ischemic-reperfused isolated rat hearts. Food Nutr. Res. 2016, 60. [CrossRef]

78. Lunder, M.; Roškar, I.; Hošek, J.; Štrukelj, B. Silver Fir (Abies alba) Extracts Inhibit Enzymes Involved in Blood Glucose Management and Protect against Oxidative Stress in High Glucose Environment. Plant Foods Hum. Nutr. 2018. [CrossRef] 
79. Whiteland, H.L.; Chakroborty, A.; Forde-Thomas, J.E.; Crusco, A.; Cookson, A.; Hollinshead, J.; Fenn, C.A.; Bartholomew, B.; Holdsworth, P.A.; Fisher, M.; et al. An Abies procera-derived tetracyclic triterpene containing a steroid-like nucleus core and a lactone side chain attenuates in vitro survival of both Fasciola hepatica and Schistosoma mansoni. Int. J. Parasitol. Drugs Drug Resist. 2018, 8, 465-474. [CrossRef]

80. Altemimi, A.; Lakhssassi, N.; Baharlouei, A.; Watson, D.; Lightfoot, D. Phytochemicals: Extraction, Isolation, and Identification of Bioactive Compounds from Plant Extracts. Plants 2017, 6, 42. [CrossRef]

81. Oswell, N.J.; Thippareddi, H.; Pegg, R.B. Practical use of natural antioxidants in meat products in the U.S.: A review. Meat Sci. 2018, 145, 469-479. [CrossRef]

82. Pavelková, A.; Bobko, M.; Haščík, P.; Kačániová, M.; Tkáčová, J. Oxidative stability of chicken thigh meat after treatment of Abies alba essential oil. Potravin. Sci. J. Food Ind. 2015, 9, 451-457. [CrossRef]

83. Romanazzi, G.; Feliziani, E.; Santini, M.; Landi, L. Effectiveness of postharvest treatment with chitosan and other resistance inducers in the control of storage decay of strawberry. Postharvest Biol. Technol. 2013, 75, 24-27. [CrossRef]

84. Korolev, K.G.; Lomovskii, O.I.; Rozhanskaya, O.A.; Vasil Ev, V.G. Mechanochemical preparation of water-soluble forms of triterpene acids. Chem. Nat. Compd. 2003, 39, 366-372. [CrossRef]

(C) 2019 by the authors. Licensee MDPI, Basel, Switzerland. This article is an open access article distributed under the terms and conditions of the Creative Commons Attribution (CC BY) license (http:/ / creativecommons.org/licenses/by/4.0/). 